Research Article

\title{
Experimental Study and Application of a Novel Foamed Concrete to Yield Airtight Walls in Coal Mines
}

\author{
Hu Wen, ${ }^{1,2}$ Shixing Fan $\mathbb{D}^{1,2}$ Duo Zhang ${ }^{1,},^{1,2}$ Weifeng Wang, ${ }^{1,2}$ Jun Guo, ${ }^{1,2}$ \\ and Qingfeng Sun ${ }^{3}$ \\ ${ }^{1}$ College of Safety Science and Engineering, Xi'an University of Science and Technology, Xi'an, Shaanxi 710054, China \\ ${ }^{2}$ Key Laboratory of Mine and Disaster Prevention and Control of Ministry of Education, \\ Xi'an University of Science and Technology, Xi'an, Shaanxi 710054, China \\ ${ }^{3}$ Research Institute of Mining Technology, Yanzhou Coal Mining Co., Ltd., Zoucheng, Shandong 273515, China
}

Correspondence should be addressed to Shixing Fan; fanxust@yeah.net

Received 13 December 2017; Revised 1 March 2018; Accepted 20 March 2018; Published 25 June 2018

Academic Editor: Giorgio Pia

Copyright $(2018 \mathrm{Hu}$ Wen et al. This is an open access article distributed under the Creative Commons Attribution License, which permits unrestricted use, distribution, and reproduction in any medium, provided the original work is properly cited.

\begin{abstract}
Airtight walls are vital to prevent spontaneous combustion of residual coal as caused by air leakage. A new type of foamed concrete (FC) was developed to control air leakage. FC specimens of four densities $\left(250,450,650\right.$, and $\left.850 \mathrm{~kg} / \mathrm{m}^{3}\right)$ were prepared for use in a series of physical and mechanical tests. A thickener was used to control the FC shrinkage and collapse. The permeability of the FC decreased approximately exponentially with an increasing density. On the contrary, the compressive strength $(\sigma)$ and elastic modulus $(E)$ increased in exponential and linear relationship separately with the increase in density, under uniaxial compression conditions. Under triaxial compression, the compressive strength of the FC increased with an increase in confining pressure and appeared slight plastic. The impact experiment showed that the dynamic compressive strength of the FC appeared to be strain-rate dependent, and it increased with an increase in the strain rate and pressure under a confining pressure. Without a confining pressure, the variation in compressive strength exhibited a slow decrease. Applied FC resulted in a $5 \mathrm{MPa} 28$-day compressive strength of the airtight wall with no remaining fissures and with air leakage suppression to the gob.
\end{abstract}

\section{Introduction}

The spontaneous combustion of residual coal in gob as triggered by air leakage has posed major threats to the safety of miners and mine facilities [1-3]. Approximately 56\% of mines have been threatened by spontaneous combustion in China's state-owned collieries, which account for $90-94 \%$ of Chinese coal mines [4-6]. In the Shenfu-Dongsheng coalfield, Shaanxi, the "U $+\mathrm{L}$ "-type ventilation system has been used extensively in the collieries. Thus, many cross headings were left in the gob during mining process. Building an airtight wall is thought to be a most effective way to control air leakage $[7,8]$, that is caused by the cross headings that remain in the gob.

Because of limitations of materials and construction techniques, the construction of an airtight wall has been problematic over recent decades. Problems include the following aspects. Earlier airtight walls were built mostly from rigid materials [9], such as bricks and concrete [10]. The airtight walls cracked easily because of the huge surrounding rock stresses. Under such conditions, air would leak and penetrate into the gob by pressure difference and promote oxidation of the residual coal [11]. To obtain an improved sealing and to prevent incidences of spontaneous combustion [12, 13], new filling materials, such as gel materials, fly ash composite colloids, rigid polyurethane foams, Rocsil foams, Marithan, and Igloneige, have been applied to build airtight walls [1, 14-17]. However, these filling materials have shortcomings. For instance, gel materials have a relatively small compressive strength. Organic filling materials often release toxic gases and significant heat, which promotes coal oxidation $[15,17,18]$. 
The development of new materials and improved construction techniques is critical for increasing mining depths and the application of new mining technologies. Foamed concrete (FC), as an inexpensive high-quality green material, has raised the attention of many experts and scholars. Since the 1980s, foreign countries with advanced mining safety technologies, such as Poland, Britain, Germany, France, South Africa, Australia, and the United States, have developed and applied various fissure plugging materials [19]. Because of their long solidification times, low foam expansion rates, and poor resistance to dynamic pressure, these materials cannot be used extensively in deep coal mines. To overcome these shortcomings, Wen et al. [20] and Tan et al. [21] developed a type of inorganic solidified foamfilling material and analyzed the effects of constituent materials on its basic physical and chemical properties in various experiments. Jambor [22] and Tang [23] probed the effects of pore structure on the FC strength. Kuzielová et al. [24] studied the effect of activated foaming agents on the FC properties. Based on the unique advantages of magnesium phosphate cement, Ma and Chen [25] used sodium bicarbonate as a foaming agent and developed new quicksetting and high-early-strength FC. Tan et al. [26] conducted a series of tests to investigate the influence of high temperature on the FC properties.

Although many experts and scholars have carried out extensive research on FC for use in coal mines, minimal attention has been given to the influence of thickeners, rock pressure, and explosion shock waves on the properties of FC filling materials. Suitable filling equipment for underground coal mine environment has seldom been mentioned in prior research and patents.

In this study, FC samples of 4 densities $(250,450,650$, and $850 \mathrm{~kg} / \mathrm{m}^{3}$ ) were prepared for test. The effects of thickener on the concrete performance, the change in permeability, and compressive strength with density, and the variation rules in failure patterns with confining pressures and impact loading are presented. A set of suitable filling systems was also developed and improved. Its efficiency was tested at working face 31404 of the Halagou coal mine in 2016.

\section{Experimental Details}

2.1. Constituent Materials. Specimens were prepared by combining the following constituent materials:

(1) Ordinary Portland cement was from the Mengxi Cement Corporation, Inner Mongolia, China, and conformed to the Chinese National Standard (GB175-2007).

(2) Local tap water.

(3) The fly ash was a major solid waste that had been discarded by the Daliuta Thermal Power Plant, Shaanxi, China.

(4) The foaming agent was generated by mixing the foam activators and foam stabilizers in a 1:1 mass ratio. The foam activators consisted of lauryl amidopropyl betaine $\left(\mathrm{C}_{20} \mathrm{H}_{40} \mathrm{~N}_{2} \mathrm{O}_{3}\right)$ and potassium monoalkyl phosphate $\left(\mathrm{C}_{12} \mathrm{H}_{25} \mathrm{OPO}_{3} \mathrm{~K}_{2}\right)$ in a $7: 3$ ratio. The foam stabilizers were composed of triethanolamine $\left(\mathrm{C}_{6} \mathrm{H}_{15} \mathrm{NO}_{3}\right)$ and oleic acid $\left(\mathrm{C}_{18} \mathrm{H}_{34} \mathrm{O}_{2}\right)$ in a $1: 1$ ratio.

(5) Fiber was modified polypropylene from the Yonggu Engineering Fiber Equipment Co., Ltd, Jiangsu, China.

(6) PC100 polycarboxylate high-performance waterreducing agent was from the Subo New Building Materials Company, Wuhan, China.

(7) HSA-efficient quick-setting coagulant was from the China Building Materials Academy.

(8) The thickener was made up of silicon powder, bentonite, and xanthan gum. The mass ratio of the three components was $60: 70: 1$.

2.2. Mixture Proportions. No standard method exists for proportioning FC. The orthogonal experiment design (OED) method was used to select the optimum mix proportions [27-30]. Then, the analysis of variance (ANOVA) was performed to estimate the relative significance of each factor in terms of percentage contribution to overall quality of FC. Consequently, the $\mathrm{W} / \mathrm{C}$ ratio and foam volume played more significant roles in the FC in terms of dry density, compressive strength, tensile strength, and so on. Moreover, the optimal mix proportions could also be determined. Accordingly, we designed the FC specimen with different target densities according to the $\mathrm{W} / \mathrm{C}$ ratio. Correspondingly, the constituent materials were mixed according to the above results strictly. Here, we take $1 \mathrm{~m}^{3} \mathrm{FC}$ as an example, and the method can be described as follows:

$$
\rho_{\mathrm{d}}=\delta \cdot m_{\mathrm{s}}
$$

where $\rho_{\mathrm{d}}$ is the target density of the FC specimen $\left(\mathrm{kg} / \mathrm{m}^{3}\right) ; \delta$ is the empirical coefficient, 1.2 is suitable for the current constituent material ratio; and $m_{\mathrm{s}}$ is the mass of solid constituent materials required per cubic meter of FC $\left(\mathrm{kg} / \mathrm{m}^{3}\right)$.

The foam expansion volume can be obtained from the following equation [26]:

$$
V_{\mathrm{f}}=k\left(1-V_{\mathrm{cs}}\right)=k\left[1-\left(\frac{m_{\mathrm{c}}}{\rho_{\mathrm{c}}}+\frac{m_{\mathrm{w}}}{\rho_{\mathrm{w}}}+\frac{m_{\mathrm{fa}}}{\rho_{\mathrm{fa}}}\right)\right],
$$

where $V_{\mathrm{f}}$ and $V_{\mathrm{cs}}$ are the volumes of foam expansion and cement slurry, respectively $\left(\mathrm{m}^{3}\right)$, and $k$ is a coefficient related to the foam quality, which varies from 1.1 to 1.3. According to the previous experiments, the foam agent was stable, so 1.18 was used. $m_{\mathrm{c}}, m_{\mathrm{w}}$, and $m_{\mathrm{fa}}$ are mass of cement, water, and fly ash per cubic meter, respectively (kg); $\rho_{\mathrm{c}}, \rho_{\mathrm{w}}$, and $\rho_{\mathrm{fa}}$ are the densities of cement, water, and fly ash $\left(\mathrm{kg} / \mathrm{m}^{3}\right)$, with $\rho_{\mathrm{c}}=3100 \mathrm{~kg} / \mathrm{m}^{3}, \rho_{\mathrm{w}}=1000 \mathrm{~kg} / \mathrm{m}^{3}$, and $\rho_{\mathrm{fa}}=2600 \mathrm{~kg} / \mathrm{m}^{3}$, respectively. The water-cement ratio (W/C) is 0.5 , namely, $m_{\mathrm{w}}=0.50 \mathrm{~m}_{\mathrm{c}}$.

The mass of foaming agent can be obtained by the following equations [31]:

$$
m_{\mathrm{fo}}=V_{\mathrm{fo}} \cdot \rho_{\mathrm{fo}},
$$


TABle 1: Mix proportions for different densities of foamed concrete.

\begin{tabular}{lcccccccccc}
\hline Number & $\begin{array}{c}\text { Target density } \\
\left(\mathrm{kg} / \mathrm{m}^{3}\right)\end{array}$ & $\begin{array}{c}\text { Cement } \\
(\mathrm{kg})\end{array}$ & $\begin{array}{c}\text { Water } \\
(\mathrm{kg})\end{array}$ & $\begin{array}{c}\text { Fly ash } \\
(\mathrm{kg})\end{array}$ & $\begin{array}{c}\text { Foaming } \\
\text { agent }(\mathrm{kg})\end{array}$ & $\begin{array}{c}\text { Foam } \\
\text { volume }\left(\mathrm{m}^{3}\right)\end{array}$ & $\begin{array}{c}\text { Fiber } \\
(\mathrm{kg})\end{array}$ & $\begin{array}{c}\text { Water-reducing } \\
\text { agent }(\mathrm{kg})\end{array}$ & $\begin{array}{c}\text { Coagulant } \\
(\mathrm{kg})\end{array}$ & $\begin{array}{c}\text { Thickener } \\
(\mathrm{kg})\end{array}$ \\
\hline 1 & 250 & 178.57 & 89.29 & 17.86 & 1.45 & 0.98 & 1.43 & 1.79 & 5.36 \\
2 & 450 & 321.43 & 160.71 & 32.14 & 1.21 & 0.82 & 2.57 & 3.21 & 9.68 \\
3 & 650 & 464.29 & 232.14 & 46.43 & 0.99 & 0.67 & 3.71 & 4.64 & 13.93 \\
4 & 850 & 607.14 & 303.57 & 60.71 & 0.77 & 0.51 & 4.86 & 6.07 & 6.96 \\
\hline
\end{tabular}

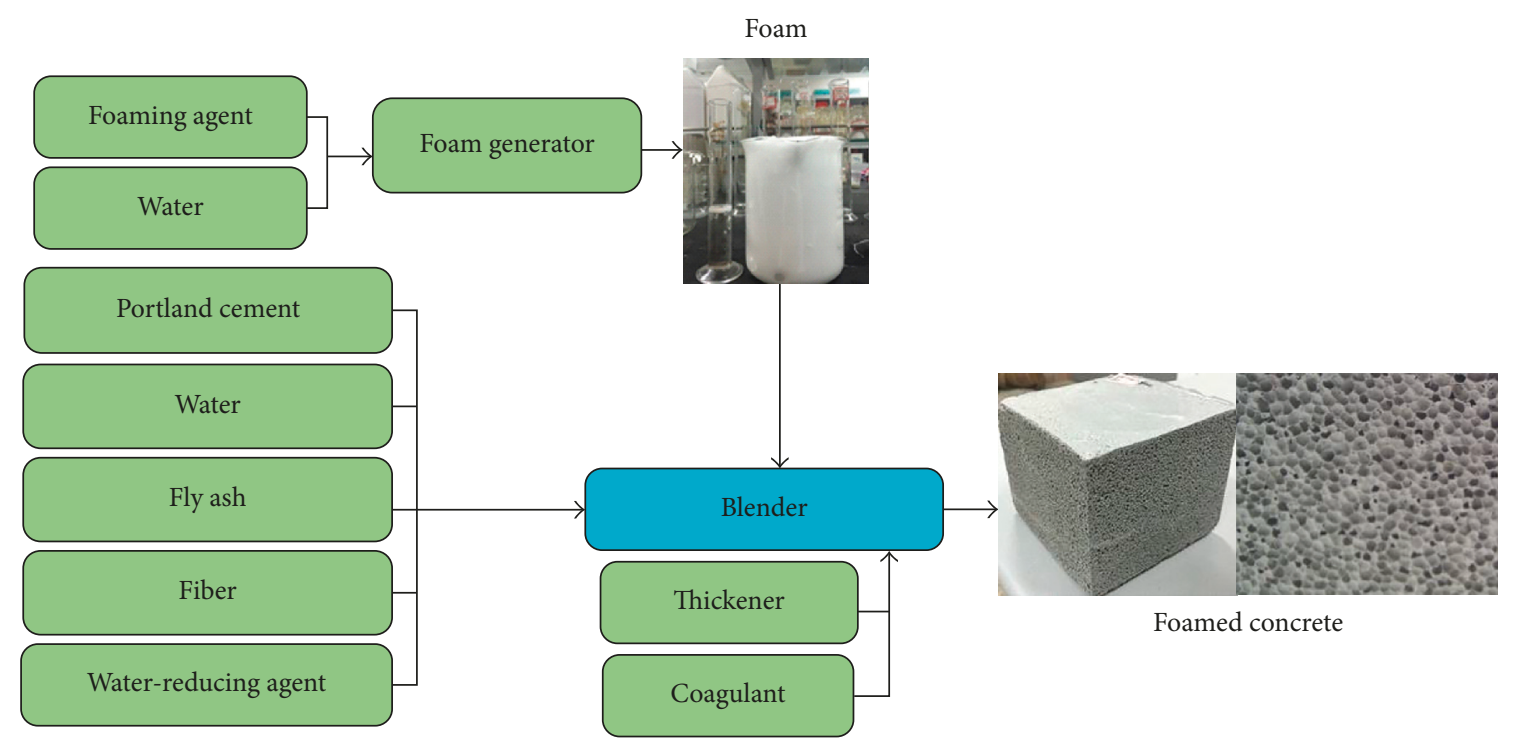

FIgURE 1: Procedure of specimen perpetration.

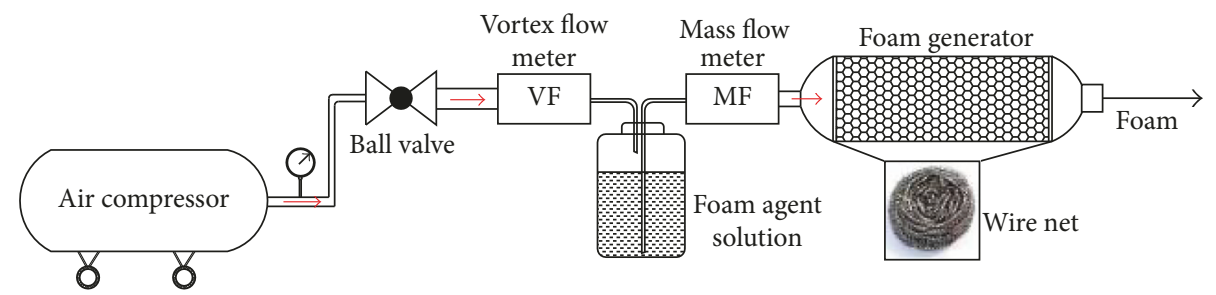

FIgURE 2: Schematic diagram of the foam generation system.

where $m_{\mathrm{fo}}$ and $\rho_{\mathrm{fo}}$ are the foam mass and density, respectively.

$$
m_{\mathrm{foa}}=\frac{m_{\mathrm{fo}}}{\alpha+1}
$$

where $m_{\text {foa }}$ is the mass of the foaming agent and $\alpha$ is the dilution ratio, $\alpha=20$.

The mass of fiber, water-reducing agent, coagulant, and thickener added into the mixtures account for $0.8 \%, 1.0 \%$, $3.0 \%$, and $1.5 \%$ of the cement mass, respectively. The details of the mix constituent proportions with the $4 \mathrm{FC}$ densities of 250 , 450,650 , and $850 \mathrm{~kg} / \mathrm{m}^{3}$ are outlined in Table 1.

2.3. Specimen Preparation. As shown in Figure 1, the specimen preparation can be summarized as follows:

(i) Mix the foam agent and water in 1:40 proportion and store these in a tank for foam generation. (ii) Add measured ordinary Portland cement, water, fly ash, fiber, and water-reducing agent to a blender and stir for $5 \mathrm{~min}$ at the speed of $60 \mathrm{r} / \mathrm{min}$.

(iii) During stirring, activate the air compressor to an accumulated pressure of $3.5 \mathrm{MPa}$. Add the foaming agent solution to the foam tank, open the ball valve, and allow solution to flow through the foam generator, as shown in Figure 2.

(iv) Measure the foam volume using the graduated cylinder, and add foam into the cement slurry twice. Add a small quantity of foam (accounting for $1 / 4-1 / 5$ of the foam quantity) to ensure the slurry is easy to dilute, and then add the remaining foam and change the stirring speed to $120 \mathrm{r} / \mathrm{min}$.

(v) Maintain stirring for 2-3 min, add the coagulant and thickener rapidly, and continue stirring for 30-40 s. 
(vi) Pour the evenly stirred slurry into $50 \mathrm{~mm}$ diameter $\times 100 \mathrm{~mm}$ high moulds, cast for $24 \mathrm{~h}$, remove the specimens from the moulds, and seal in a curing box for 28 days before removal for further testing.

2.4. Actual Density Calculation of Specimens. After the specimens were removed out from the moulds, three standard specimens $(\varnothing 50 \mathrm{~mm} \times 100 \mathrm{~mm})$ in each density were chosen for actual density calculation. First, the actual dimensions of three specimens are gauged to calculate their volume, and then, these specimens were put into the oven for $24 \mathrm{~h}$ at $65^{\circ} \mathrm{C}$. After $24 \mathrm{~h}$, the baking temperature was adjusted to $100^{\circ} \mathrm{C}$ until the weight of specimens was constant. Then, the mass of these specimens were measured in ambient temperature. Ultimately, densities of the specimens can be obtained by the following expression:

$$
\rho_{\mathrm{a}}=\frac{M_{\mathrm{a}}}{V_{\mathrm{a}}},
$$

where $M_{\mathrm{a}}, V_{\mathrm{a}}$, and $\rho_{\mathrm{a}}$ are the actual mass, volume, and density of the specimen, respectively.

2.5. Experimental Apparatus. Specimen preparation and experiments on the physical and mechanical properties were carried out by the following test apparatus:

(1) NJ-160B cement blender with an autocontrol rotating speed of $0 \sim 120 \mathrm{r} / \mathrm{min}$ (Kexi Instrument Equipment Co., Ltd. Hebei, China).

(2) Servo-controlled testing system (RMT-150B) is manufactured by the Institute of Rock and Soil Mechanics, the Chinese Academy of Sciences. This system can be used to conduct many types of tests, such as uniaxial compression, triaxial compression, tension, and fatigue tests $[26,32,33]$. Its maximum load is $1000 \mathrm{kN}$ and the maximum confining pressure is $40 \mathrm{MPa}$. Using a self-designed testing container and the air supply system, the system can also be used to carry out the permeability test, and the maximum of gas injection pressure can reach $12 \mathrm{MPa}$

(3) The Split Hopkinson pressure bar (SHPB) apparatus consists of an emitting cavity, a cone-shaped striker, an input bar, a transmitter bar, an absorption bar, and a data acquisition system [34, 35]. The lengths and diameters of the $t$ input and output bars are $2500 \mathrm{~m}$ and $50 \mathrm{~mm}$, respectively. The bars and striker are made of high-strength $40 \mathrm{Cr}$ steel with a density of $7850 \mathrm{~kg} / \mathrm{m}^{3}$ and Young's modulus of $210 \mathrm{GPa}$. The wave propagation velocity $c_{0}=\sqrt{E / \rho}=5172 \mathrm{~m} / \mathrm{s}$.

2.6. Experimental Methodology. Compressive strength is the basic physical property of FC, which can be defined as the ability of the concrete specimen to sustain the axial load. In this study, the 28-day compressive strength of FC specimens of densities $250,450,650$, and $850 \mathrm{~kg} / \mathrm{m}^{3}$ was conducted in the RMT-150B machine according to the ASTM standards
$[36,37]$. To ensure the accuracy of the test, three specimens were prepared for compression at each density. To clarify the relationship between the uniaxial compressive strength and density quantitatively, the compressive strength was expressed as

$$
\sigma=\frac{F}{A}
$$

where $\sigma$ is the compressive strength $(\mathrm{MPa}), F$ is the maximum failure load, and $A$ is the compressive area of the specimen $\left(\mathrm{mm}^{2}\right)$.

Triaxial compressive tests of samples of two FC densities $\left(250\right.$ and $\left.450 \mathrm{~kg} / \mathrm{m}^{3}\right)$ under different confining pressures $(0.00,0.25,0.50$, and $1.00 \mathrm{MPa})$ were also conducted in the RMT-150B machine.

The FC permeability was determined in the servopermeability test device, which was designed based on an RMT machine. The maximum gas injection pressure can reach $12 \mathrm{MPa}$. The FC permeability was measured under the steady-state method. Darcy's equation was used to estimate the permeability of FC according to the experimental results [38]:

$$
k=\frac{2 Q p_{0} \mu L}{A\left(p_{1}^{2}-p_{2}^{2}\right)},
$$

where $Q$ is the gas flow rate, $p_{0}$ is the atmospheric pressure, $\mu$ is the gas viscosity, $L$ is the sample length, and $p_{1}$ and $p_{2}$ are the injection and outlet pressures, respectively. During the experiment, $p_{1}, p_{2}$, and $Q$ were recorded when the gas was at steady state.

In this study, the $\mathrm{N}_{2}$ permeability of FC was calculated at given set of confining pressures at 1.0 MPa fixed injection pressure. The confinement pressures ranged from 0 to $3.5 \mathrm{MPa}$ and varied with the interval of $0.25 \mathrm{MPa}$. A similar series of tests were conducted on the FC specimens with the other three densities, and finally, the permeability as function of confining pressure and density was estimated.

The dynamic compressive properties of FC were studied experimentally by using SHPB. Twenty specimens with a density of $850 \mathrm{~kg} / \mathrm{m}^{3}$ were prepared and tested under various confining pressures $(0,2.5,5.0$, and $7.5 \mathrm{MPa})$. In each series of tests with the same confining pressure, the impact loading was increased from $0.3 \mathrm{MPa}$ to $0.7 \mathrm{MPa}$. Prior to the experiment, specimens were sandwiched between the input and transmitter bars. The cone-shaped striker was ejected from the emitting cavity under pressurized nitrogen to strike the input bar and generate an incident pulse. Because of the impedance mismatch of the specimen and the input bar, only part of the incident pulse, as a transmitted pulse, was transmitted through the specimens into the transmitted bar, and the other part was reflected into the input bar. Strain gauges on the input bar and transmitted bar were used to record the incident, reflected, and transmitted pulses. Pulses collected by the data acquisition system were used to generate dynamic stress-strain curves. The response that was obtained by using SHPB was voltage signals, which need to be calculated according to a three-wave formula to obtain the stress-strain relation. 
TABLE 2: Comparison of target density and actual density.

\begin{tabular}{lcccccc}
\hline \multirow{2}{*}{ Number } & \multirow{2}{*}{ Target density $\left(\mathrm{kg} / \mathrm{m}^{3}\right)$} & \multicolumn{3}{c}{ Actual mass $(\mathrm{g})$} & Volume $\left(\mathrm{mm}^{3}\right)$ & Actual density $\left(\mathrm{kg} / \mathrm{m}^{3}\right)$ \\
\hline 1 & 250 & 50.17 & 49.02 & 48.53 & 194877.8 & 252.7 \\
2 & 450 & 89.90 & 86.67 & 88.41 & 195461.9 & 451.9 \\
3 & 650 & 129.14 & 125.97 & 123.13 & 195267.2 & 645.7 \\
4 & 850 & 167.56 & 166.02 & 171.81 & 195072.5 & 863.5 \\
\hline
\end{tabular}

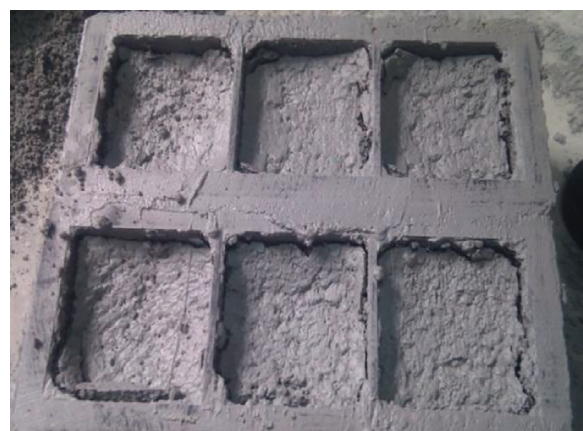

(a)

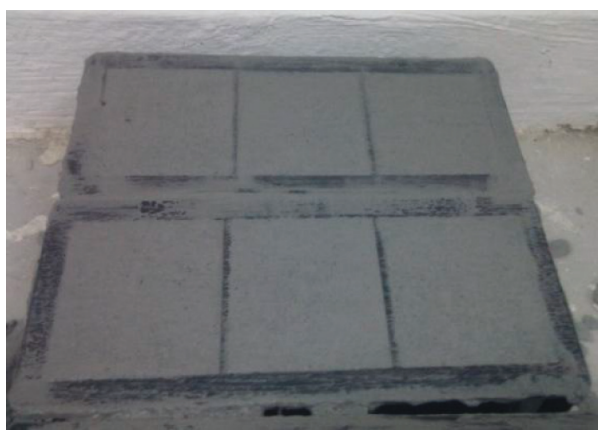

(b)

Figure 3: Contrast of the foam concrete specimen before (a) and after (b) the new special thickener was added.

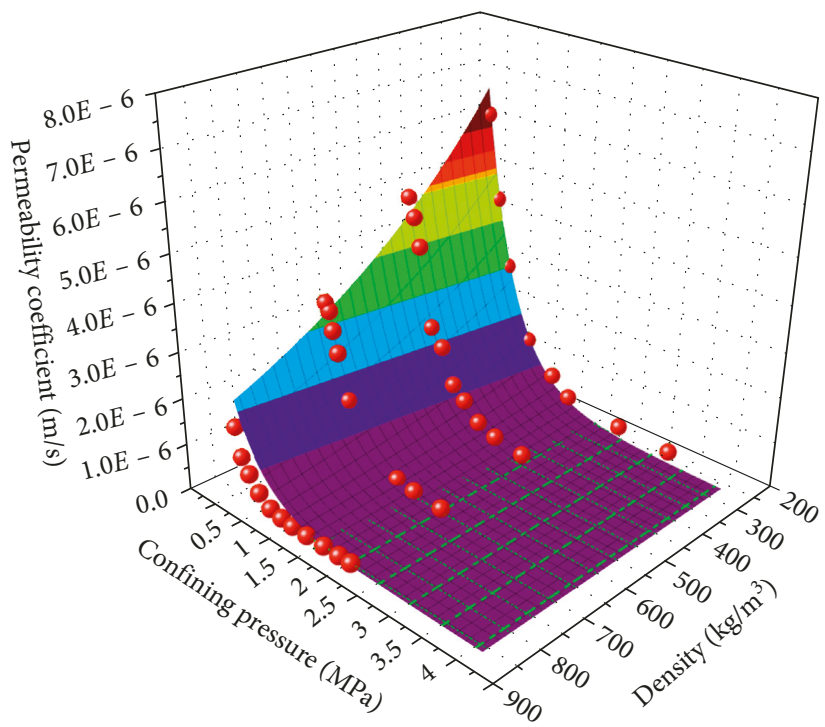

FIGURE 4: Relationship between the permeability coefficient of foamed concrete and confining pressures.

\section{Results and Discussion}

The results of actual density calculation of specimens of four densities $\left(250,450,650\right.$, and $\left.850 \mathrm{~kg} / \mathrm{m}^{3}\right)$ are shown in Table 2 .

3.1. Effect of Thickener on the Performance of Foamed Concrete. In common FC, only cement is used directly as a cementitious material, and it accounts for $70 \%-80 \%$ of the mass of the FC. During the filling of the airtight wall, the lower cohesive performance of the cement yields a maximum filling height of the airtight wall of $30 \mathrm{~cm}-50 \mathrm{~cm}$. Once the filling height exceeds $50 \mathrm{~cm}$, the bubble is easy to burst subject to the slurry gravity, which leads to a large shrinkage in the upper part of the airtight wall. Thus, the homogeneity and construction quality of the airtight wall cannot be guaranteed.

To overcome the shortcomings mentioned above, a new special thickener, which was composed of silicon powder, bentonite, and xanthan gum in a mass ratio of 60 : $70: 1$, was mixed in the FC. The specimen shrinkage was reduced significantly and it did not collapse, after thickener addition. The performance of the special thickener is shown in Figure 3. 


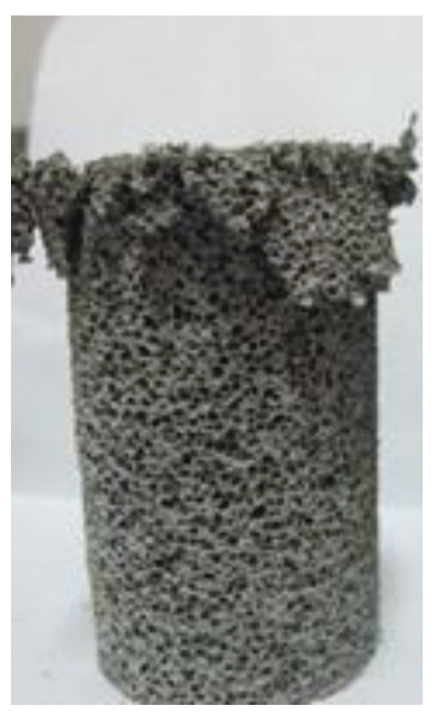

(a)

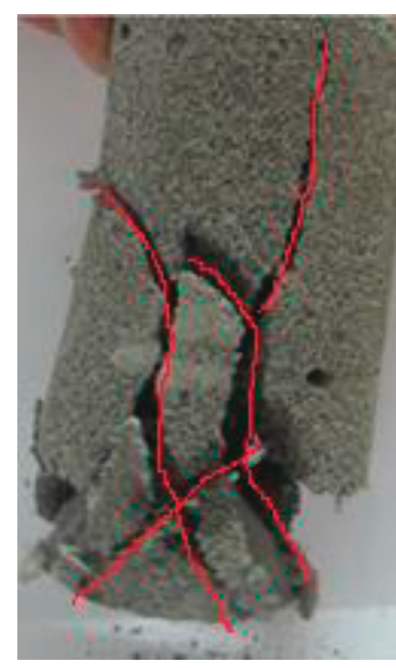

(b)

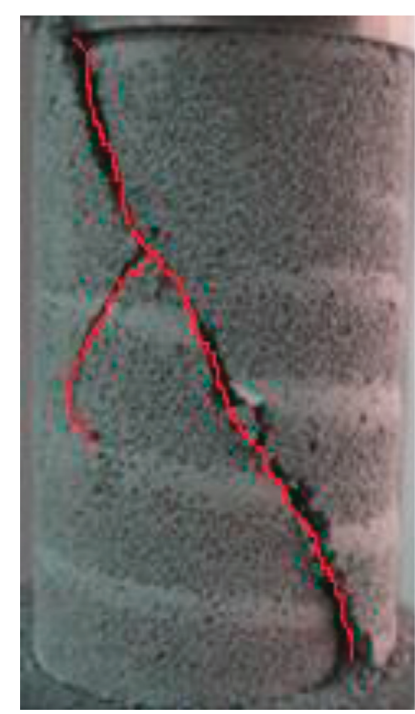

(c)

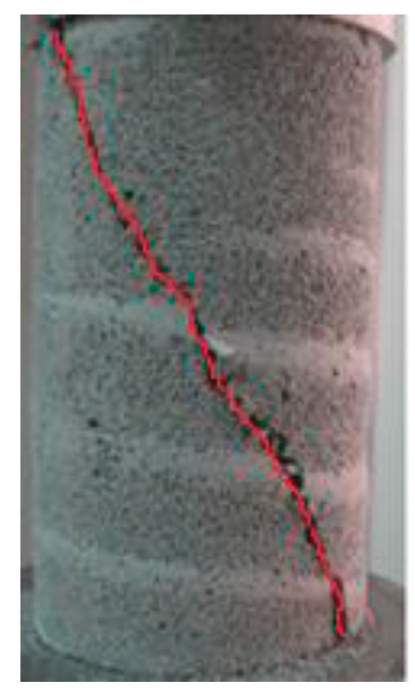

(d)

Figure 5: Failure patterns of specimens with different densities under quasistatic loading. (a) $250 \mathrm{~kg} / \mathrm{m}^{3}$. (b) $450 \mathrm{~kg} / \mathrm{m}^{3}$. (c) $650 \mathrm{~kg} / \mathrm{m}^{3}$. (d) $850 \mathrm{~kg} / \mathrm{m}^{3}$.

3.2. Permeability Experiment of Foam Cement. Figure 4 presents the relationship between permeability and confining pressure for FC at 4 different densities. The variation in the red ball symbols in Figure 4 indicates that the FC permeability decreased to varying degrees with an increase in confining pressure and density. The larger buried depth and airtight wall density yield a better tightness. The relationship between the permeability, density, and confining pressure can be expressed as

$$
k=1.32 \times 10^{-7}+1.10 \times 10^{-5} \cdot e^{((-(C / 54.06))-(\rho / 536.14))},
$$

where $k$ decreased gradually with an increase in confining pressure and density when $0 \leq C \leq 4 \mathrm{MPa}$ and $200 \leq \rho \leq$ $850 \mathrm{~kg} / \mathrm{m}^{3}$. Combined with the field situation and experience, the FC permeability with a density of $250 \mathrm{~kg} / \mathrm{m}^{3}$ also reached $6.1 \times 10^{-6} \mathrm{~m} / \mathrm{s}$, which was sufficient to suppress the oxidation of residual coal by preventing air from entering the mined area.

\subsection{Experimental Study on Mechanical Properties of Foamed Concrete}

3.3.1. Uniaxial Compressive Test of Foamed Concrete. Figure 5 shows the typical failure patterns of FC specimens with four densities $\left(250,450,650\right.$, and $\left.850 \mathrm{~kg} / \mathrm{m}^{3}\right)$. The FC at different densities presented different failure patterns, which can be grouped into the following three categories:

(1) Specimens were damaged from top to bottom with a continuing downward movement of the indenter, and no penetrating fractures were found in the specimen surface and interior. These failure characteristics were attributed mainly to a lower compressive strength. With fiber addition, the tensile strength approximated the compressive strength. The large porosity of the low-density FC created a relatively large inward deformation space, which enabled the specimen to maintain a better integrity after large deformation, as shown in Figure 5(a).

(2) As shown in Figure 5(b), under a quasistatic loading, several visible splitting cracks propagated parallel to the compressive loading, on the specimen surface. Only one penetrated the specimen from top to bottom. These failure characteristics were mainly caused by a lower tensile strength.

(3) Figures 5(c) and 5(d) show that the main inclined crack throughout the specimen appeared on the specimen surface, along with several small shear failures that distribute around the main failure. As the FC density increased, the fractional small shear failures decreased gradually.

Because the three duplicate tests of each density gave consistent results, the average values of the three tests were used and are plotted in Figure 6(a). As mentioned in previous papers, the compressive strength was a function of porosity or density. Its mathematical expressions could be depicted as linear, exponential, power, and logarithmic. After the test data analysis, we found that the compressive strength increased approximately exponentially with an increase in density [26], and $R^{2}$ reached 0.994 . The expression is as given below:

$$
\sigma=0.1634 e^{0.0048 \rho}
$$

The relationship between the elastic modulus and density is presented in Figure 6(b). And we fitted the average test values $\left(R^{2}=0.997\right)$ and obtained the following expression:

$$
E=2.19 \rho-456.63,
$$

where $E$ is the elastic modulus. 


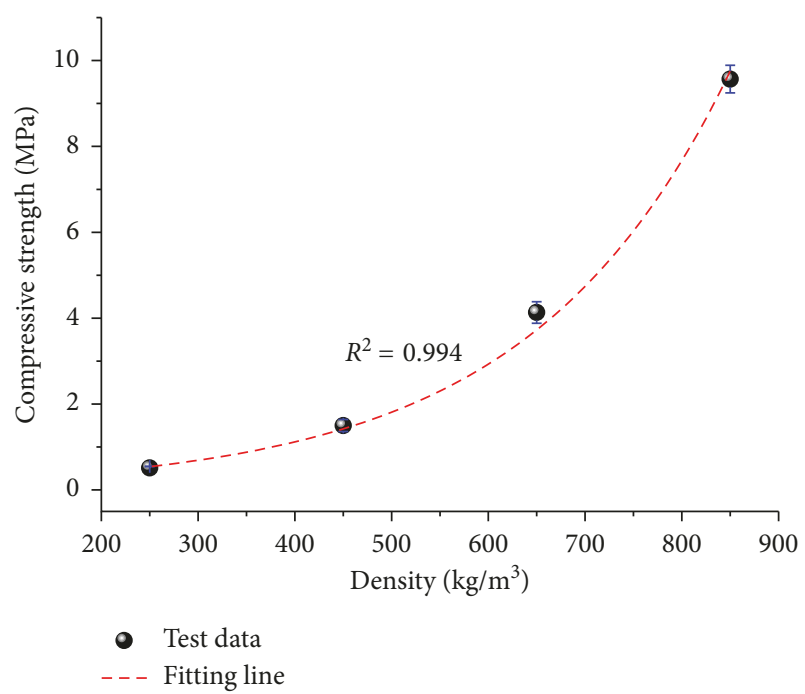

(a)

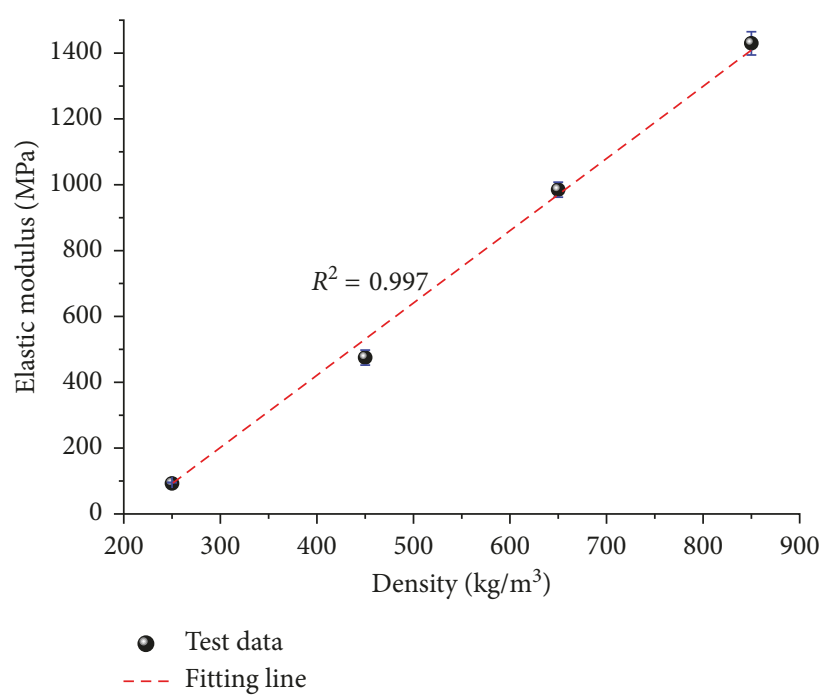

(b)

FIGURE 6: Curves of compressive strength and modulus versus density. The relationship between (a) compressive strength and density and (b) elastic modulus and density.

3.3.2. Triaxial Compressive Test of Foamed Concrete. Figure 7 shows that under uniaxial compression, the stress showed an increasing trend with increasing strain in an approximately linear relationship until the stress equaled the destroyed loading. Then, the stress decreased slightly and was maintained at a steady level with a continuous increasing strain. This occurred because along with the collapse of partial framework, the internal stress was transferred to another partial framework of the FC. Therefore, the FC was a type of ideal elastoplastic material. However, under triaxial compression, because of the influence of the confining pressure on radial deformation, the FC density would increase when the volume was compressed to a critical value. Consequently, the compressive and residual strengths increased with an increase in density. Thus, the stress-strain curves transformed gradually from a softening to a hardening strain with an increase in confining pressure.

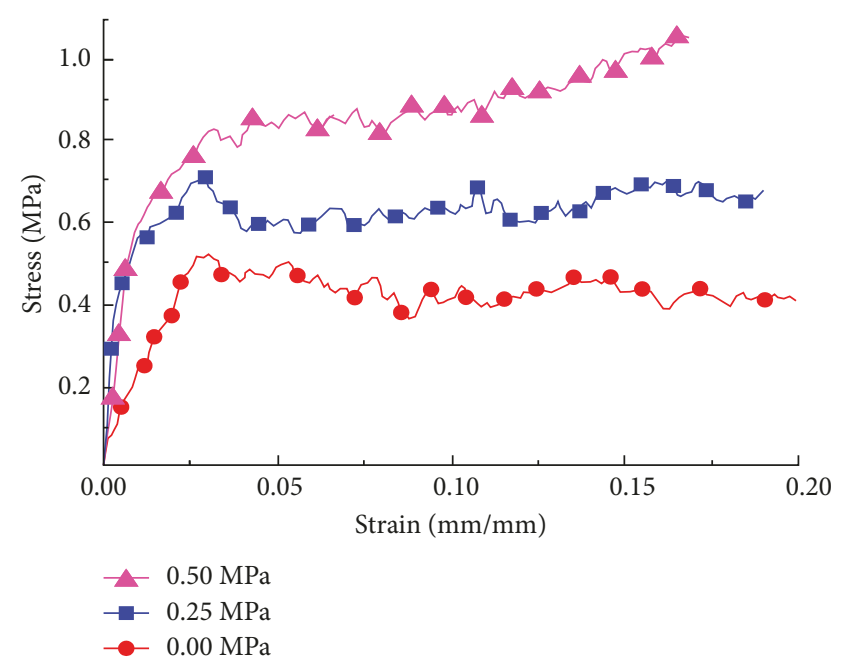

(a)

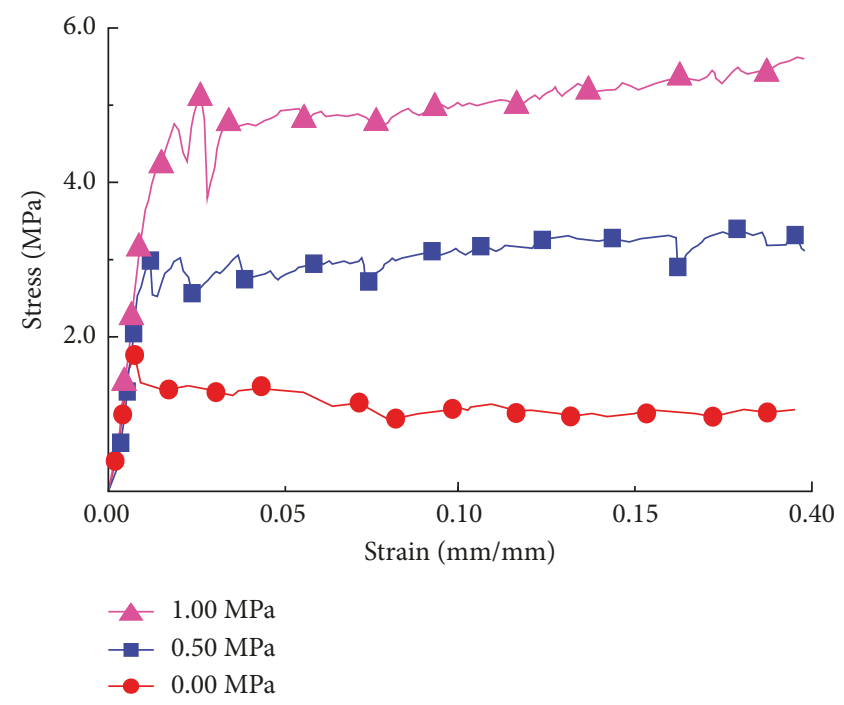

(b)

FIgURE 7: Stress-strain curves of foamed concrete under different confining pressures. (a) $250 \mathrm{~kg} / \mathrm{m}^{3}$. (b) $450 \mathrm{~kg} / \mathrm{m}^{3}$.

3.4. Foam Cement Impact Resistance. The failure patterns of the specimens under different confining pressures are compared in Figure 8. With no confining pressure, specimens were crushed into small pieces with an increase in impact pressure, as shown in Figure 8(a). This occurred because fissures with a dip angle larger than the internal friction angle could not endure any loading [39]. However, because of the increase in confining pressure, the loading capacity of the fissures with the steep angle increased rapidly, which improved the specimen compressive strength of the specimen and deformation performance and prevented shear-slip damage. Under the same impact loading and with an increase in confining pressure, the damaged section of the specimen was reduced gradually. The specimen remained intact after an impact of $0.3 \mathrm{MPa}$ and $0.7 \mathrm{MPa}$, whereas the confining pressure reached $2.5 \mathrm{MPa}$. The observation demonstrates that the compressive strength increased with an increase in confining pressure. The confining pressure 

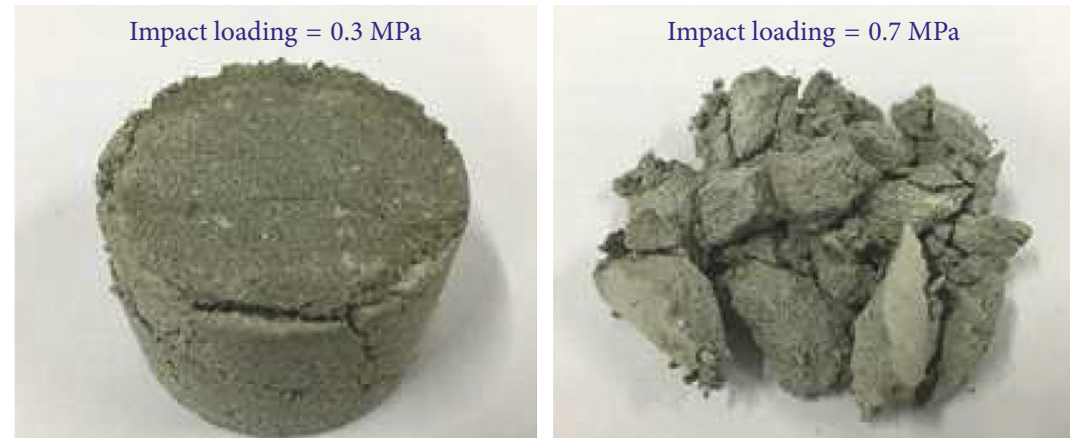

(a)
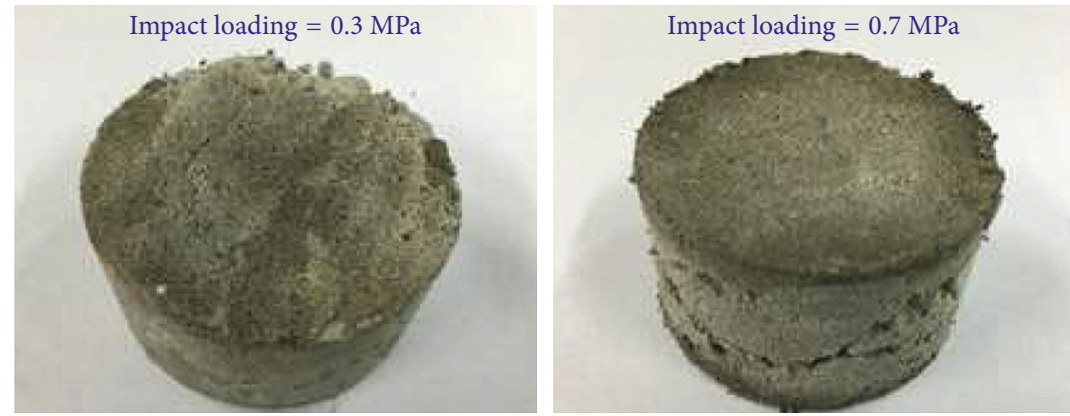

(b)
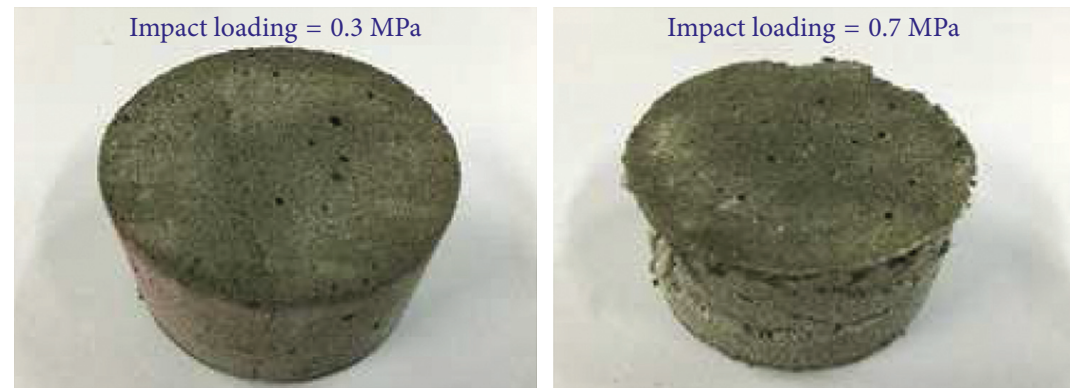

(c)

FIGURE 8: Failure patterns of specimens under different confining pressures. (a) $0 \mathrm{MPa}$. (b) $2.5 \mathrm{MPa}$. (c) $7.5 \mathrm{MPa}$.

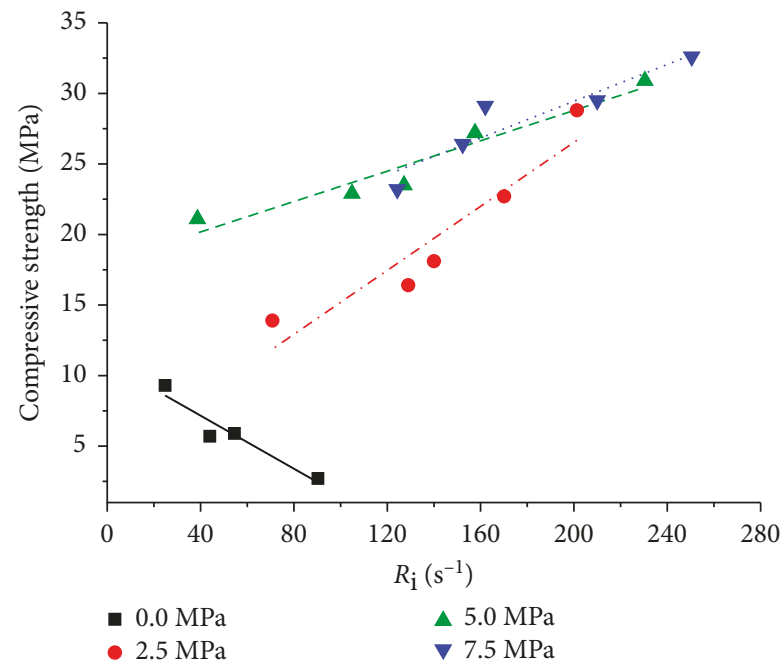

FIGURE 9: Effect of strain rates on the compressive strength under different confining pressures. 


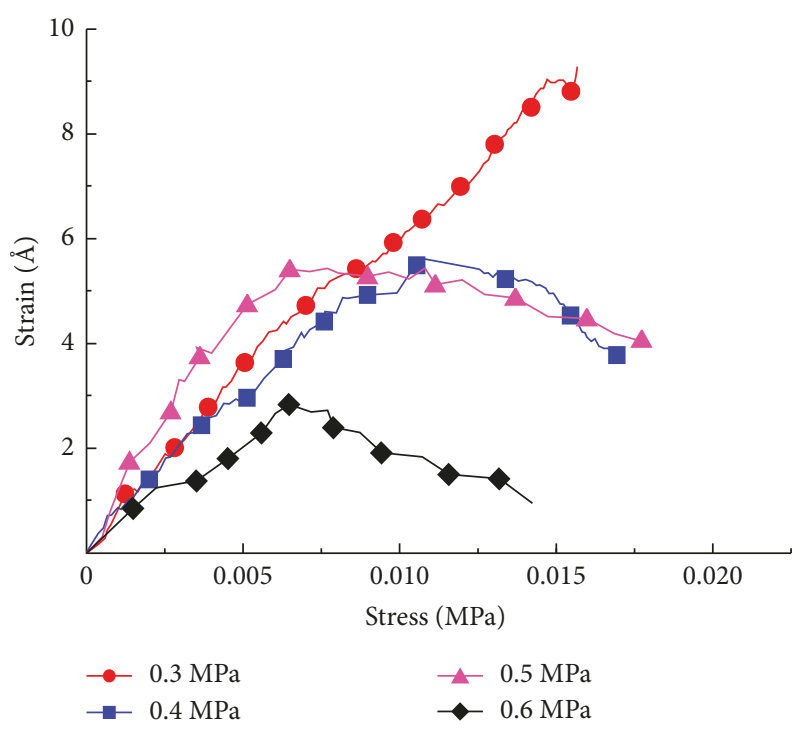

(a)

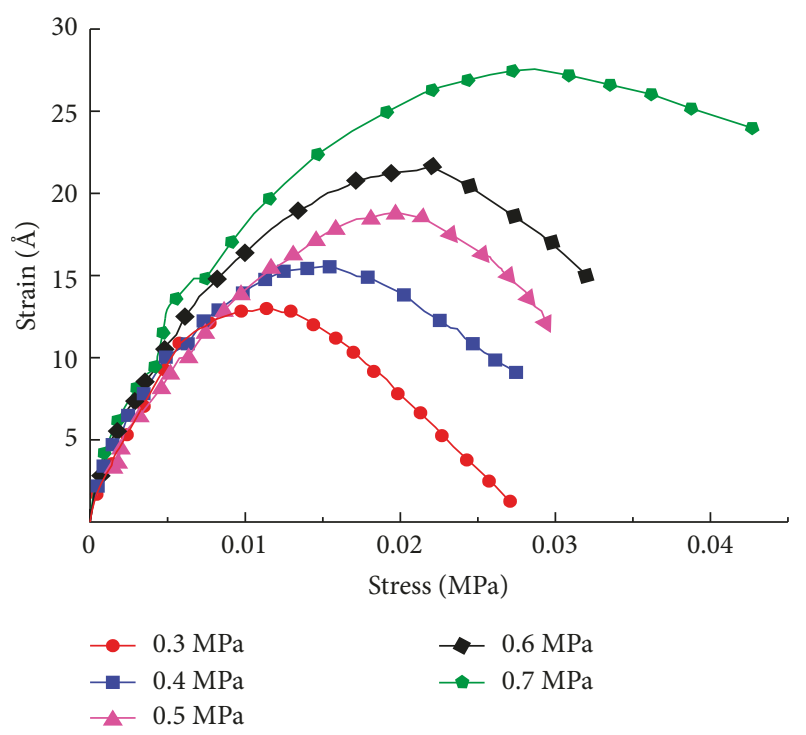

(b)

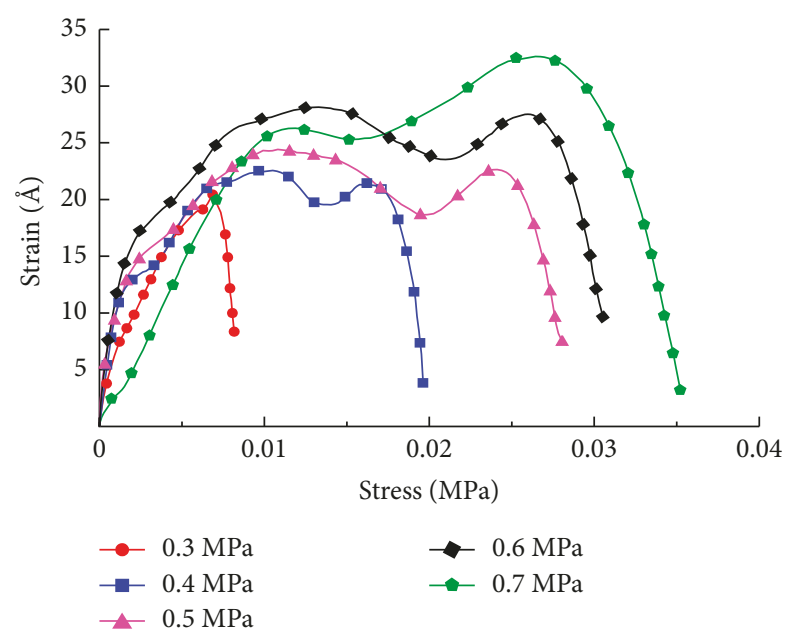

(c)

FIGURE 10: Continued.

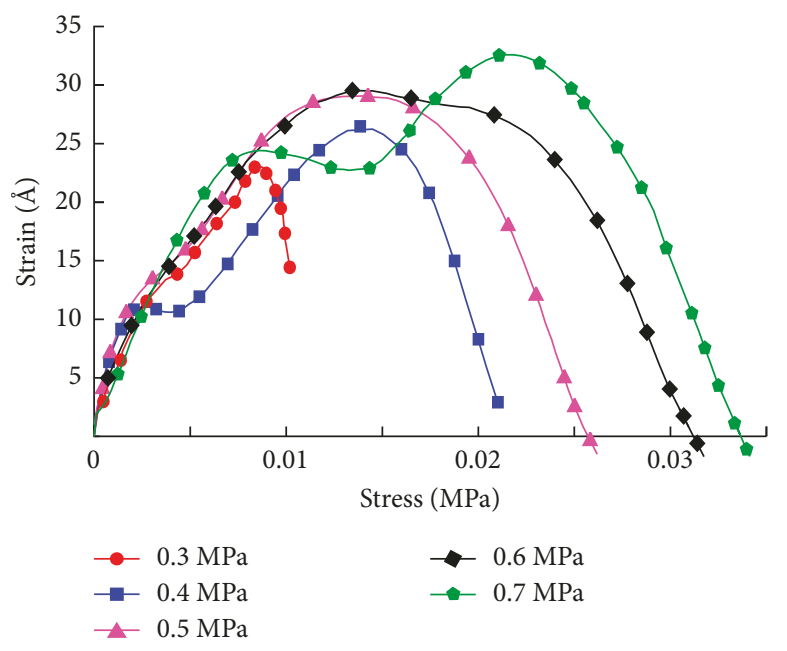

(d)

FIGURE 10: Stress-strain curves of foamed concrete under different confining pressures. (a) $0.0 \mathrm{MPa}$. (b) $2.5 \mathrm{MPa}$. (c) $5.0 \mathrm{MPa}$. (d) $7.5 \mathrm{MPa}$.

that constrains the formation and expansion of cracks in concrete may be a major reason for the larger compressive strength.

The variation in compressive strength versus the strain rate $\left(R_{\mathrm{i}}\right)$ for FC specimens with a density of $850 \mathrm{~kg} / \mathrm{m}^{3}$ is shown Figure 9. The dynamic compressive strength of the FC is clearly strain-rate dependent. Under no confining pressure, the compressive strength of the FC decreased with an increase in the strain rate. However, under a confining pressure, the compressive strength increased with an increase in the strain rate. Under a similar strain rate, the compressive strength of the FC under the high confining pressure was larger than that of the low confining pressure.

Figure 10 shows the stress-strain curves of the FC with a density of $850 \mathrm{~kg} / \mathrm{m}^{3}$ under impact loading with different confining pressures. The compressive strength of the FC increased with an increase in confining pressures. The stressstrain curves of the FC have similar features at different confining pressures. During the initial loading stage, the load was sustained mainly by the specimen frameworks, and the stress increased almost linearly to an elastic limit with an increasing strain, in accordance with Hook's law. The elastic limit corresponds to the first inflection point of the stressstrain curves. Beyond the elastic limit, the stress increased continuously, but the increasing rate decreased gradually, and sometimes the stress-strain curves showed oscillatory features, which is related closely to the collapse of the internal FC framework. During this period, the specimen could still bear the load to a certain degree, and the partial energy of the incident stress wave converted to a plastic deformation of the specimen. The pore structure of the FC was destroyed gradually, and the bearing capacity of the specimen decreased gradually until the FC framework was destroyed completely. In summary, the confining pressure increased the plastic deformation of FC. 


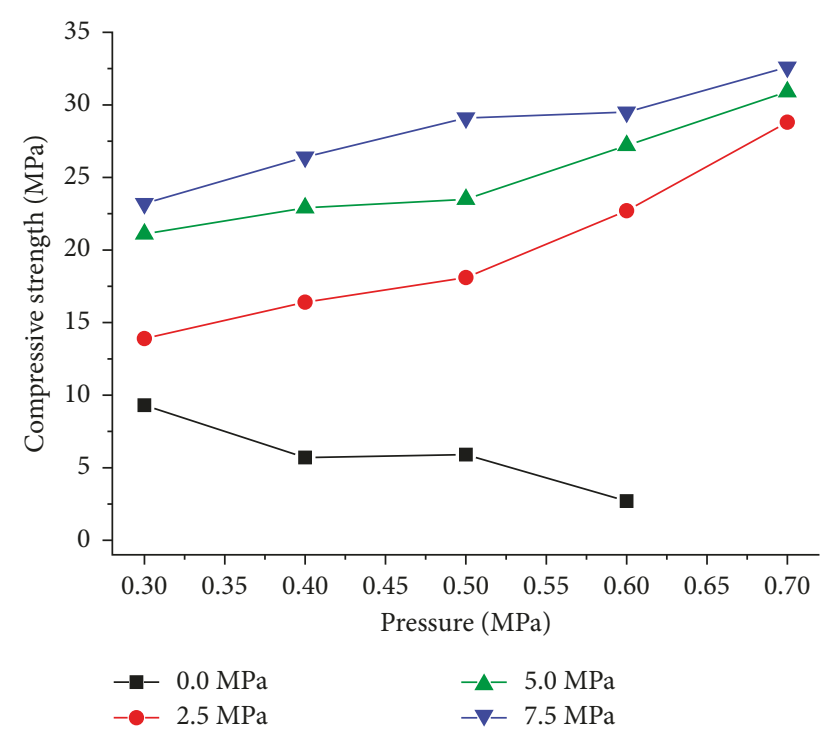

FIGURE 11: Effect of pressure on the compressive strength under different confining pressures.

As shown in Figure 11, under different confining pressures, the curves of the FC compressive strength versus pressures showed similar features compared with Figure 9. Under confining pressure conditions, the compressive strength increased with an increase in pressure. A higher confining pressure yielded a larger compressive strength. In contrast, the compressive strength showed a downward trend without confining pressure. The variations in compressive strength indicated that the confining pressure promoted the compressive strength, which prevented explosions caused by spontaneous combustion. The results obtained could provide suggestions for the selection of foamed concrete density.

\section{Engineering Application}

4.1. Rapid-Filling System. As mentioned above, an airtight wall is a key factor to prevent the spontaneous combustion of residual coal in gob. Normally, airtight walls are built using bricks and loess $[13,40]$. As shown in Figure 12(a), first, two external walls were built using the bricks, and then, the loess was filled in the interior space between the two brick walls. It would take four days to build an airtight wall with a width of $5.6 \mathrm{~m}$, a height of $6 \mathrm{~m}$, and a thickness of $5 \mathrm{~m}$ by using the traditional construction techniques.

To shorten the construction period, a new type of rapid construction technique was used at no. 31404 working face in the Halagou Coal Mine, in the Shengdong mining area. Figure 12(b) shows that a new type of airtight wall was built by the cast-in-place concrete formwork technology. First, we dug a $500 \mathrm{~mm}$ groove in the roof, floor, and on both sides of the tunnel. Then, two walls were built using concrete formworks to enclose a confined zone. Subsequently, an injection pipe was connected with a slurry pump and a grouting machine to complete the filling process.

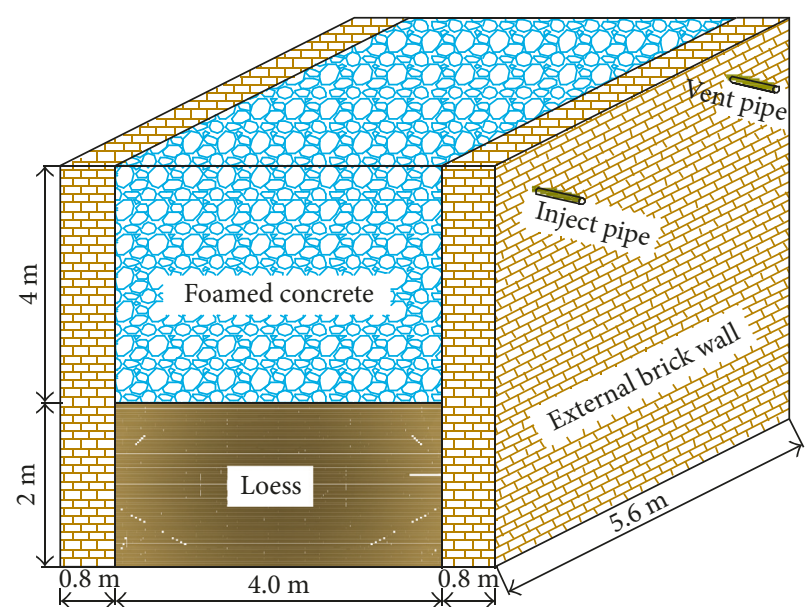

(a)

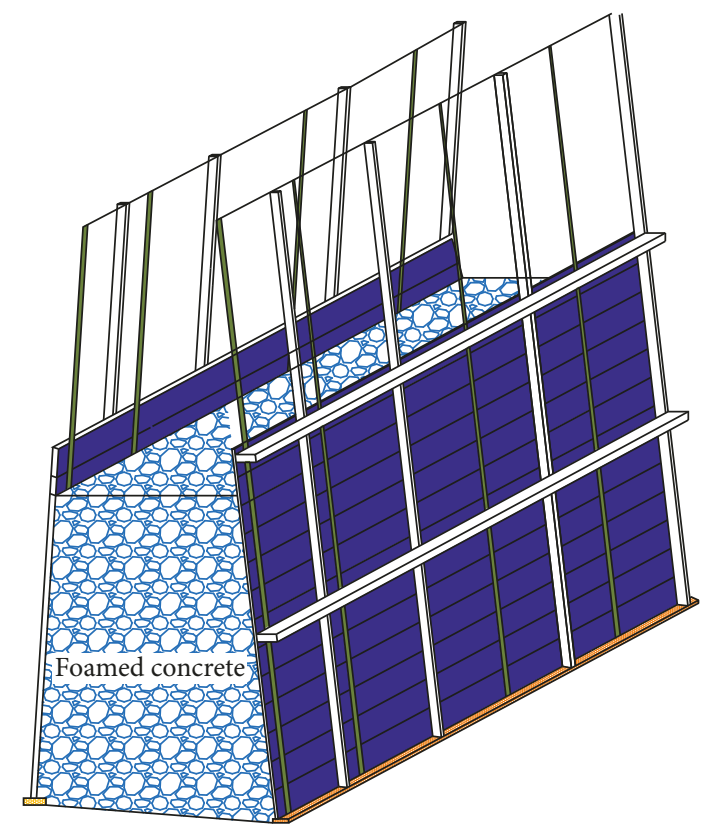

(b)

FIgURE 12: Schematic diagram of (a) traditional construction technique and (b) the new type of construction technique.

Figure 13 shows the filling system, which was composed mainly of a screw conveyor, ZMJ-G-type slurrymaking machine, and a pneumatic pump. The ZMJ-G-type slurry-making machine was improved based on the ZMJ-F type. The screw conveyor could deliver and mix the cement and fly ash in certain proportion evenly, which alleviates the labor intensity of the workers and improves the efficiency. The field tests reveal that the average FC productivity reaches $8-10 \mathrm{~m}^{3} / \mathrm{min}$, achieving long-distance transportation and continuous filling at a large capacity. The cost of the filling material can be controlled to within $¥ 350-500$ yuan $/ \mathrm{m}^{3}$.

4.2. The Filling Effect. Figures 14(a) and 14(b) show the airtight wall at $24 \mathrm{~h}$ and $28 \mathrm{~d}$, when the concrete 


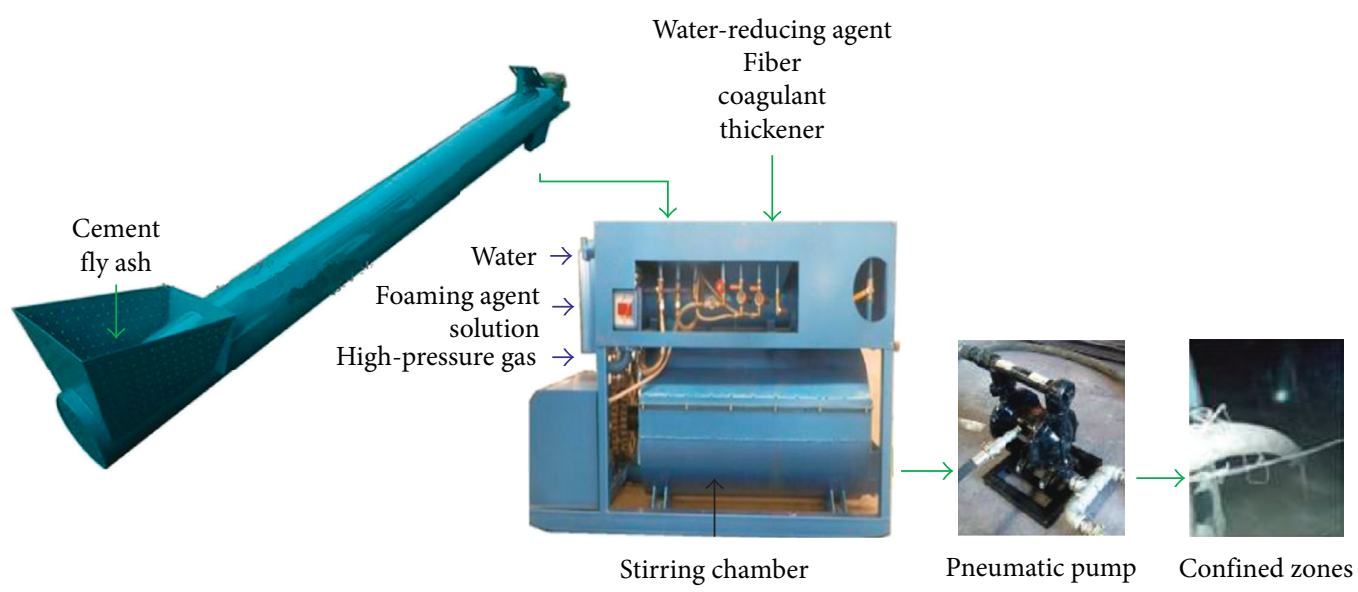

FIGURE 13: Filling system.

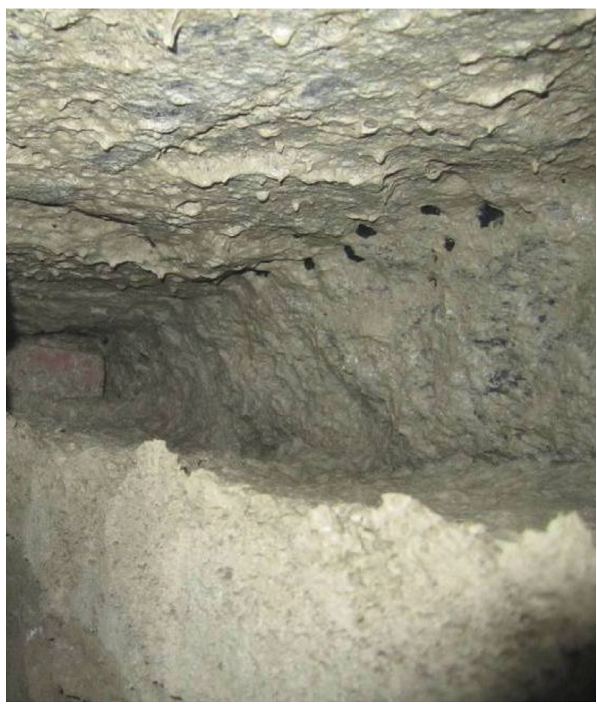

(a)

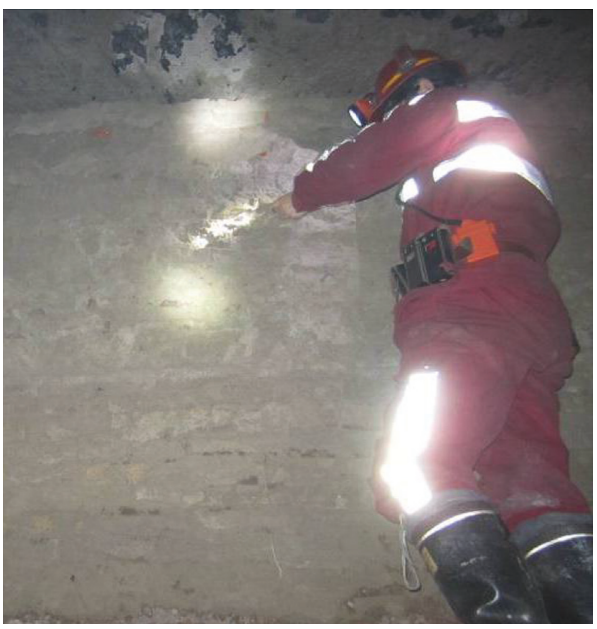

(b)

Figure 14: Filling effect of foamed concrete. Filling effect after (a) 24 hours and (b) 28 days. formworks were removed. Rebound tests of the airtight wall revealed that the strength at $28 \mathrm{~d}$ reached $5.0 \mathrm{MPa}$. The airtight wall lasted for 5 months until the working face exceeded the $76 \#$ cross heading $400 \mathrm{~m}$. During the period of observation, the airtight wall remained in the excellent condition without any damage. A new type of filling materials, with advantages of a higher strength, an improved tightness, and an excellent antiexplosive performance, is suitable for wide promotion and application.

\section{Conclusions}

Tests were carried out to study the properties of FC. The following conclusions were obtained:

(1) The thickener could enhance the cohesive performance of the cement, prevent foam from breaking, and resist FC shrinkage during moulding.

(2) The FC permeability decreased to varying degrees with an increase in pressure and density.

(3) The experimental results on the mechanical properties of the FC showed that the compressive strength increased approximately the exponential trend with an increase in density and the elastic modulus increased linearly with an increase in density. Because of the constraint of confining pressure on the radial deformation, the compressive strength of FC increased with an increase in confining pressure and the stress-strain curves showed plastic features.

(4) The impact experiments showed that the compressive strength of the FC was clearly strain-rate dependent. The dynamic compressive strength increased with an increase in the strain rate and pressure under a confining pressure. Without the confining pressure, the variation in compressive strength decreased significantly.

(5) The engineering practice showed that the new filling system could shorten the construction period, alleviate worker labor intensity, and achieve an FC 
productivity of $8-10 \mathrm{~m}^{3} / \mathrm{min}$. The 28 -day compressive strength of the airtight wall reached $5.0 \mathrm{MPa}$.

\section{Conflicts of Interest}

The authors declare that they have no conflicts of interest.

\section{Acknowledgments}

The authors gratefully acknowledge the financial support from National Key R\&D Projects (Program no. 2016YFC0801802) and National Natural Science Foundation of China (no. 51504186). This work is also a project funded by the Shenhua Shendong Coal Mining Group Corporation Ltd.

\section{References}

[1] Z. Y. Song and C. Kuenzer, "Coal fires in China over the last decade: a comprehensive review," International Journal of Coal Geology, vol. 133, pp. 72-99, 2014.

[2] J. Deng, Y. Xiao, J. H. Lu, H. Wen, and Y. F. Jin, “Application of composite fly ash gel to extinguish outcrop coal fires in China,” Natural Hazards, vol. 79, no. 2, pp. 881-898, 2015.

[3] H. Wen, Z. H. Yu, J. Deng, and X. W. Zhai, "Spontaneous ignition characteristics of coal in a large-scale furnace: an experimental and numerical investigation," Applied Thermal Engineering, vol. 114, pp. 583-592, 2017.

[4] T. Q. Xia, F. B. Zhou, F. Gao, J. H. Kang, J. S. Liu, and J. G. Wang, "Simulation of coal self-heating processes in underground methane-rich coal seams," International Journal of Coal Geology, vol. 141-142, pp. 1-12, 2015.

[5] T. Q Xia, X. X. Wang, F. B. Zhou, J. H. Kang, J. S. Liu, and F. Gao, "Evolution of coal self-heating processes in longwall gob areas," International Journal of Heat and Mass Transfer, vol. 86, pp. 861-868, 2015.

[6] H. Wen, Z. H. Yu, S. X. Fan, X. W. Zhai, and W. Y. Liu, "Prediction of spontaneous combustion potential of coal in the gob area using co extreme concentration: a case study," Combustion Science and Technology, vol. 189, no. 10, pp. 1713-1727, 2017.

[7] M. Y. Tang, B. Y. Jiang, R. Q. Zhang, Z. Q. Yin, and G. L. Dai, "Numerical analysis on the influence of gas extraction on air leakage in the gob," Journal of Natural Gas Science and Engineering, vol. 33, pp. 278-286, 2016.

[8] Z. Y. Song, H. Q. Zhu, B. Tan, H. Y. Wang, and X. F. Qin, "Numerical study on effects of air leakages from abandoned galleries on hill-side coal fires," Fire Safety Journal, vol. 69, pp. 99-110, 2014.

[9] N. Van Den Bossche, W. Huyghe, J. Moens, A. Janssens, and M. Depaepe, "Airtightness of the window-wall interface in cavity brick walls," Energy and Buildings, vol. 45, pp. 32-42, 2012.

[10] J. Yang, Q. Du, and Y. W. Bao, "Concrete with recycled concrete aggregate and crushed clay bricks," Construction and Building Materials, vol. 25, no. 4, pp. 1935-1945, 2011.

[11] X. W. Zhai, J. Deng, H. Wen, and W. Ma, "Research of the air leakage law and control techniques of the spontaneous combustion dangerous zone of re-mining coal body," Procedia Engineering, vol. 26, pp. 472-479, 2011.

[12] W. M. Cheng, X. M. Hu, J. Xie, and Y. Y. Zhao, "An intelligent gel designed to control the spontaneous combustion of coal: fire prevention and extinguishing properties," Fuel, vol. 210, pp. 826-835, 2017.
[13] L. Z. Jin, R. Y. Jin, and Z. A. Jiang, “Application of seal-filling material in mine safety-foaming resin and its application technology," China Safety Science Journal, vol. 8, no. 5, pp. 32-36, 1998.

[14] G. Wang, G. Q. Yan, X. H. Zhang et al., "Research and development of foamed gel for controlling the spontaneous combustion of coal in coal mine," Journal of Loss Prevention in the Process Industries, vol. 44, pp. 474-486, 2016.

[15] Z. L Xi, D. Li, and Z. Y. Feng, "Characteristics of polymorphic foam for inhibiting spontaneous coal combustion," Fuel, vol. 206, pp. 334-341, 2017.

[16] H. Zhang, P. Li, N. Hui, J. S. Liang, Y. Ding, and T. X. Liu, "The microstructure and methane catalytic combustion of ceria composite materials modified with tourmaline particles," Journal of Alloys and Compounds, vol. 712, pp. 567-572, 2017.

[17] Z. L. Xi and A. Li, "Characteristics of thermoplastic powder in an aqueous foam carrier for inhibiting spontaneous coal combustion," Process Safety and Environmental Protection, vol. 104, pp. 268-276, 2016.

[18] B. T. Qin and Y. Lu, "Experimental research on inorganic solidified foam for sealing air leakage in coal mines," International Journal of Mining Science and Technology, vol. 23, no. 1, pp. 151-155, 2013.

[19] S. Xue, B. Dickson, and J. Wu, "Application of ${ }^{222} \mathrm{Rn}$ technique to locate subsurface coal heatings in Australian coal mines," International Journal of Coal Geology, vol. 74, no. 2, pp. 139-144, 2008.

[20] H. Wen, D. Zhang, Z. J. Yu, X. Z. Zheng, S. H. Fan, and B. Laiwang, "Experimental study and application of inorganic solidified foam filling material for coal mines," Advances in Materials Science and Engineering, vol. 2017, Article ID 3419801, 13 pages, 2017.

[21] X. J. Tan, W. Z. Chen, Y. G. Hao, and X. Wang, "Experimental study of ultralight $\left(<300 \mathrm{~kg} / \mathrm{m}^{3}\right)$ foamed concrete," Advances in Materials Science and Engineering, vol. 2014, Article ID 514759, 7 pages, 2014.

[22] J. Jambor, "Pore structure and strength development of cement composites," Cement and Concrete Research, vol. 20, no. 6, pp. 948-954, 1990.

[23] L. P. Tang, "A study of the quantitative relationship between strength and pore-size distribution of porous materials," Journal of Chongqing Architecture University, vol. 16, no. 1, pp. 87-96, 1986.

[24] E. Kuzielová, L. Pach, and M. Palou, "Effect of activated foaming agent on the foam concrete properties," Construction and Building Materials, vol. 125, pp. 998-1004, 2016.

[25] C. Ma and B. Chen, "Experimental study on the preparation and properties of a novel foamed concrete based on magnesium phosphate cement," Construction and Building Materials, vol. 137, pp. 160-168, 2017.

[26] X. J. Tan, W. Z. Chen, J. H. Wang et al., "Influence of high temperature on the residual physical and mechanical properties of foamed concrete," Construction and Building Materials, vol. 135, pp. 203-211, 2017.

[27] J. C. Tang, G. C. Gong, H. Su, F. H. Wu, and C. Herman, "Performance evaluation of a novel method of frost prevention and retardation for air source heat pumps using the orthogonal experiment design method," Applied Energy, vol. 169, pp. 696-708, 2016.

[28] B. J. Winer, D. R. Brown, and K. M. Michels, Statistical Principles in Experimental Design, McGraw-Hill, New York, NY, USA, 1971. 
[29] G. Zou, J. Xu, and C. Wu, "Evaluation of factors that affect rutting resistance of asphalt mixes by orthogonal experiment design," International Journal of Pavement Research and Technology, vol. 10, pp. 282-288, 2017.

[30] K. T. Huang and Y. J. Li, "Impact of street canyon typology on building's peak cooling energy demand: a parametric analysis using orthogonal experiment," Energy and Buildings, vol. 154, pp. 448-464, 2017.

[31] Z. M. Huang, T. S. Zhang, and Z. Y. Wen, "Proportioning and characterization of Portland cement-based ultra-lightweight foam concretes," Construction and Building Materials, vol. 79, pp. 390-396, 2015.

[32] W. Chen, H. Tian, J. Yuan, and X. Tan, "Degradation characteristics of foamed concrete with lightweight aggregate and polypropylene fibre under freeze-thaw cycles," Magazine of Concrete Research, vol. 65, no. 12, pp. 720-730, 2013.

[33] Z. Meng and J. Pan, "Correlation between petrographic characteristics and failure duration in clastic rocks," Engineering Geology, vol. 89, no. 3, pp. 258-265, 2007.

[34] Q. Fu, Y. J. Xie, G. C. Long, D. T. Niu, H. Song, and X. G. Liu, "Impact characterization and modelling of cement and asphalt mortar based on SHPB experiments," International Journal of Impact Engineering, vol. 106, pp. 44-52, 2017.

[35] Y. Hao and H. Hao, "Dynamic compressive behaviour of spiral steel fibre reinforced concrete in split Hopkinson pressure bar tests," Construction and Building Materials, vol. 48, pp. 521-532, 2013.

[36] N. M. Ibrahim, S. Salehuddin, R. C. Amat, N. L. Rahim, and T. N. T. Izhar, "Performance of lightweight foamed concrete with waste clay brick as coarse aggregate," Apcbee Procedia, vol. 5, pp. 497-501, 2013.

[37] M. R. Ali, M. Maslehuddin, M. Shameem, and M. S Barry, "Thermal-resistant lightweight concrete with polyethylene beads as coarse aggregates," Construction and Building Materials, vol. 164, pp. 739-749, 2018.

[38] E. P. Kearsley and P. J. Wainwright, "Porosity and permeability of foamed concrete," Cement and Concrete Research, vol. 31, pp. 805-812, 2001.

[39] Z. M. Yaseen, R. C. Deo, A. Hilal et al., "Predicting compressive strength of lightweight foamed concrete using extreme learning machine model," Advances in Engineering Software, vol. 115, pp. 112-125, 2018.

[40] F. P. Su, X. Q. Zhou, and Y. Wang, "Influence of atmospheric pressure fluctuation on air leakage rate of airtight-wall," Procedia Engineering, vol. 11, pp. 401-408, 2011. 


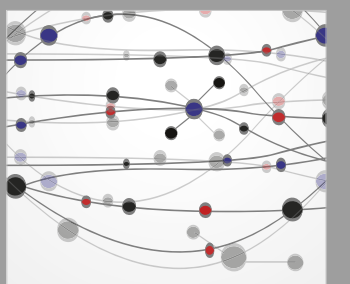

The Scientific World Journal
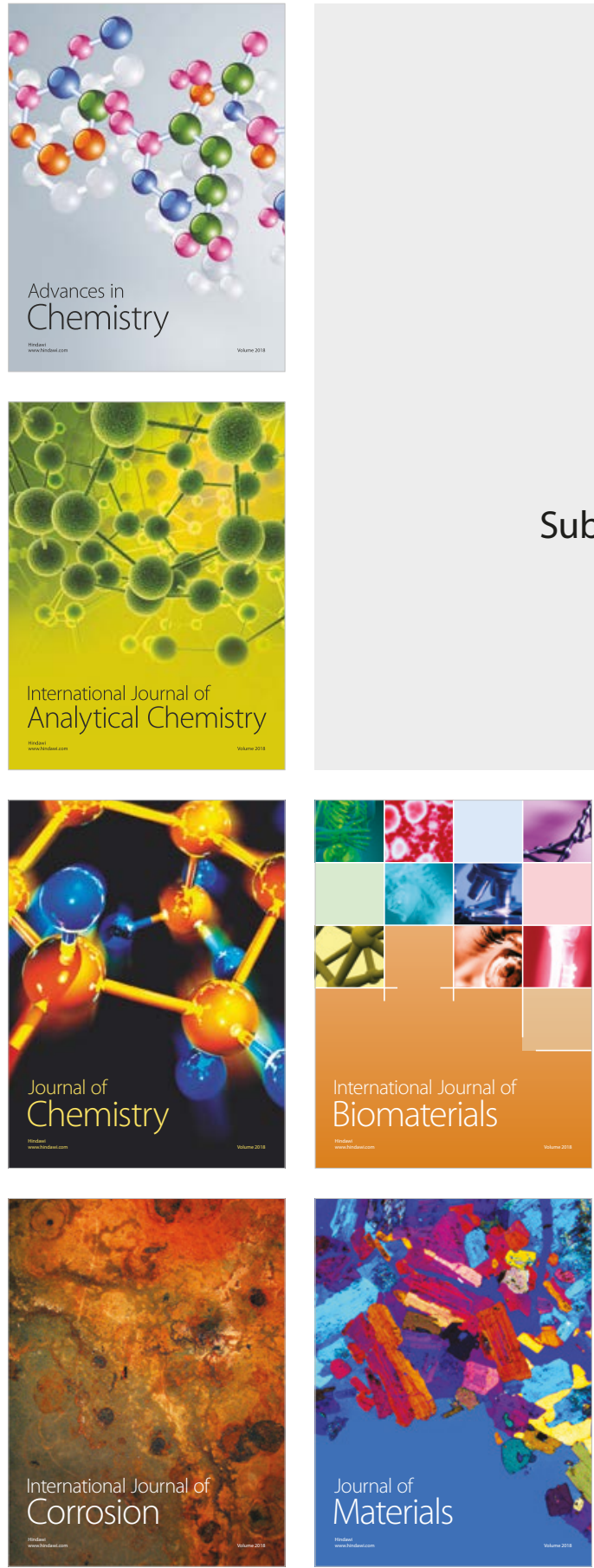

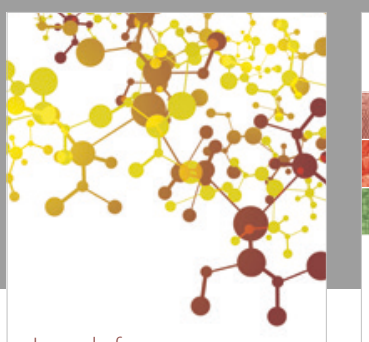

Journal of

Applied Chemistry
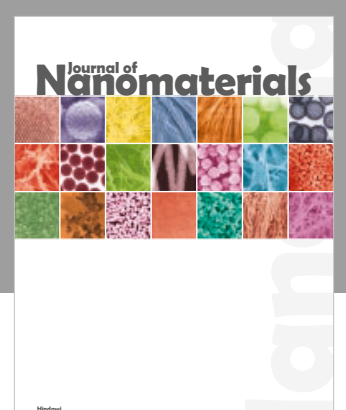

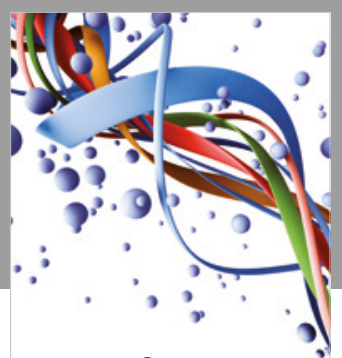

Scientifica

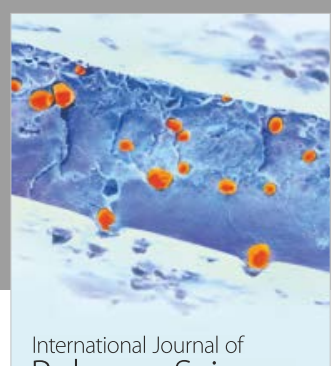

Polymer Science

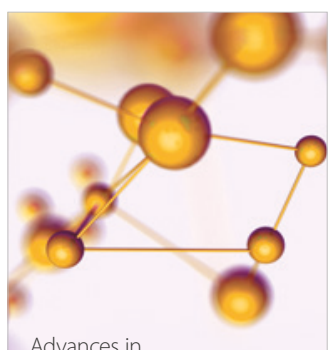

Physical Chemistry
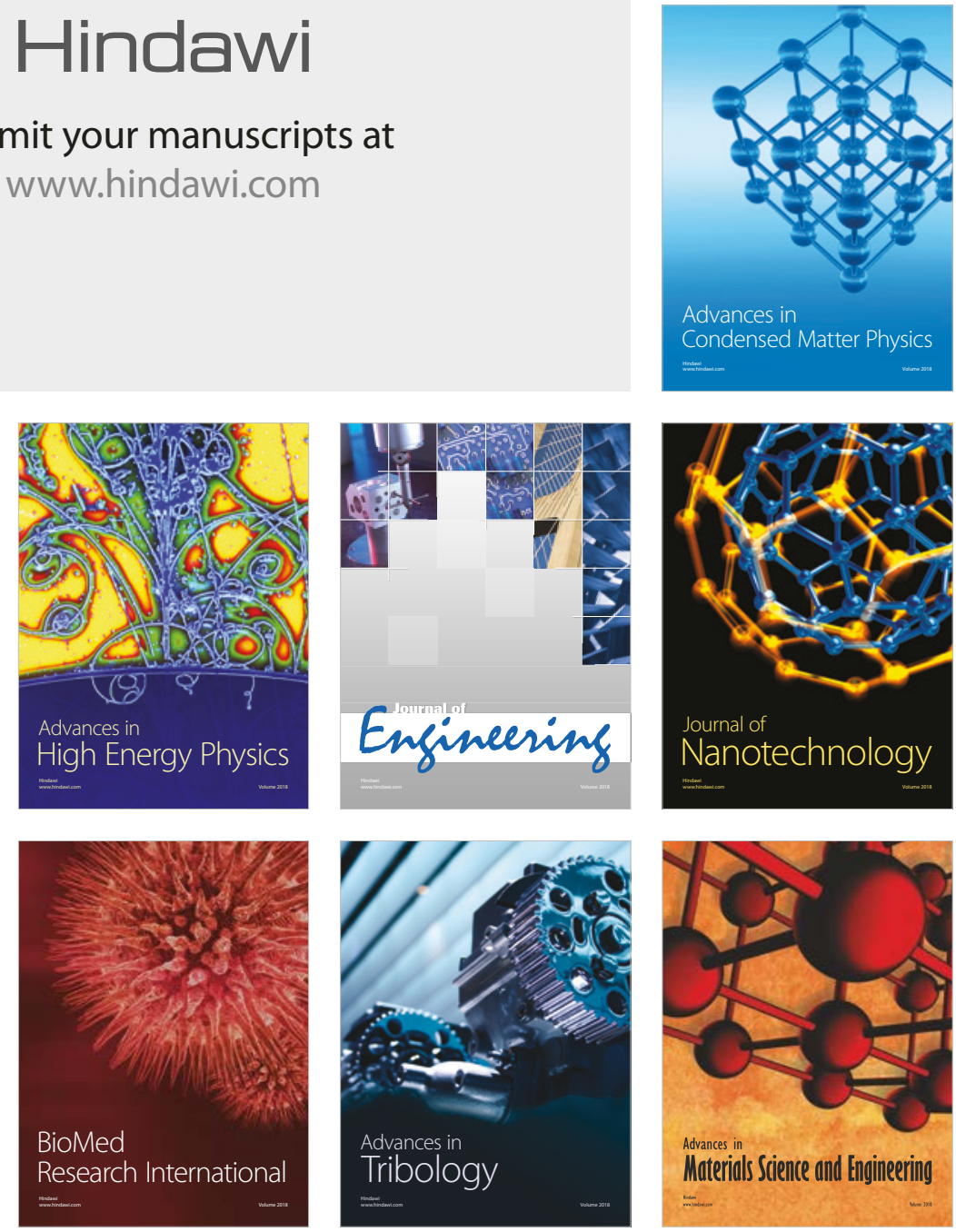